\title{
A case of flank pain caused by ureteral intussusception accompanied with ureteral polyp
}

\author{
Yang Dong ${ }^{\dagger}$, Wen-da Zhang ${ }^{\dagger}$, Tao Fan ${ }^{\dagger}$, Lin Hao, Jia-he Zhou, Wei-ming Ma and Cong-hui Han ${ }^{*}$
}

\begin{abstract}
Background: Ureteral intussusception, a rarely reported unique condition, occurs primarily as a complication of ureteric tumours.

Case presentation: We present a case of ureteral intussusception accompanied with a large ureteral polyp periodically protruding into the bladder cavity occurring in a 56-year-old man who experienced vague flank pain and intermittent haematuria. The patient was successfully treated by ureteroscopic cauterization combined with partial ureterectomy with reanastomosis.

Conclusions: This is the first report that describes polyp-related ureteral intussusception using comprehensive and representative ureteroscopic images and video. Our findings suggest that ureteroscopy is vital for diagnosis. Extensive biopsies through ureteroscopy are less invasive, and make it easier to exclude the presence of ureteral malignancies. Ureteroscopic resection of the whole polyp with its stalk and intussusceptum using Holmium: YAG laser did not seem viable in this case. However, cauterization of partial polyp tissues followed by open surgery for segmental resection of the ureter with reanastomosis is helpful in controlling such patient well-being.
\end{abstract}

Keywords: Ureteral intussusception, Ureteral polyp, Ureteroscopy

\section{Background}

Ureteral intussusception is a rarely reported unique condition, in which the proximal ureteral wall telescopes into the distal lumen. It often develops slowly and occurs secondary to ureteral neoplasms; however, it is occasionally caused by calculi or endoscopic surgical procedures. Due to the lack of awareness regarding this condition, ureteral intussusception is often unsuspected and misdiagnosed. Here, we present a case of ureteral intussusception accompanied with ureteral polyp and, to our knowledge, this is the first report that provides comprehensive and representative ureteroscopic images and video depicting the case.

\footnotetext{
* Correspondence: 201706014207bjk@ncist.edu.cn

${ }^{\dagger}$ Yang Dong, Wen-da Zhang and Tao Fan contributed equally to this work. Department of Urology, Xuzhou Central Hospital Affiliated to Xuzhou Medical University, Jiefang South Road, No. 199, Xuzhou, Jiangsu, China
}

\section{Case presentation}

A 56-year-old man presented with a 1-week history of vague pain in the right flank and suprapubic region, and intermittent haematuria. He recalled having similar mild attacks periodically 2 years before that remitted without treatment. He denied any significant medical history, the habit of smoking and explosion to any solvents or chemicals. Bladder neoplasm was initially suspected by outpatient colour Doppler ultrasonography and cystoscopy at a local hospital 3 days prior to admission. No abnormalities were observed upon physical examination, serological examination, and urine cytology after admission. Computed tomography (CT) revealed an enlargement in the inferior part of the right ureter with a suspected solid mass (Fig. 1a). Further intravenous urogram (IVU) revealed a "sponge-like" filling defect in the right lower enlarged ureteral lumen and right ureteral orifice inside

(c) The Author(s). 2020 Open Access This article is licensed under a Creative Commons Attribution 4.0 International License, which permits use, sharing, adaptation, distribution and reproduction in any medium or format, as long as you give appropriate credit to the original author(s) and the source, provide a link to the Creative Commons licence, and indicate if changes were made. The images or other third party material in this article are included in the article's Creative Commons licence, unless indicated otherwise in a credit line to the material. If material is not included in the article's Creative Commons licence and your intended use is not permitted by statutory regulation or exceeds the permitted use, you will need to obtain permission directly from the copyright holder. To view a copy of this licence, visit http://creativecommons.org/licenses/by/4.0/ The Creative Commons Public Domain Dedication waiver (http://creativecommons.org/publicdomain/zero/1.0/) applies to the data made available in this article, unless otherwise stated in a credit line to the data. 

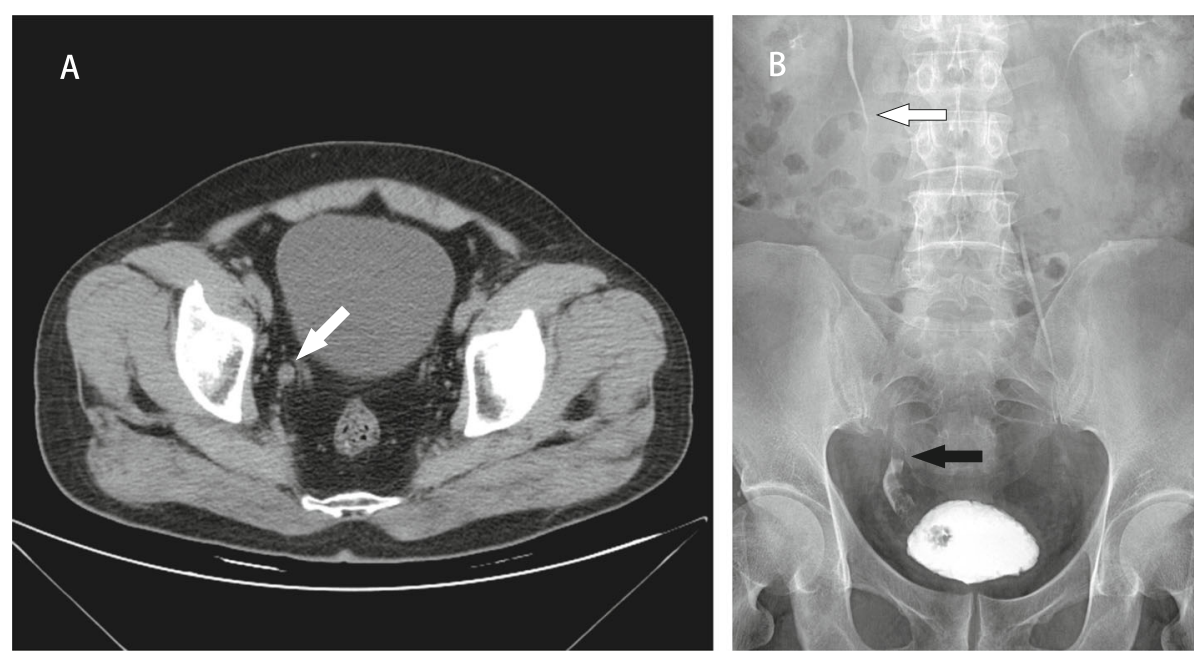

Fig. 1 Computed tomography and intravenous urogram findings (a) Computed tomography shows an enlargement in the inferior part of the right ureter with a suspected solid mass; (b) Intravenous urogram shows a "sponge-like" filling defect in the right distal dilated ureteral lumen (black arrow) without dilation of the upper urinary tract and renal pelvis (white arrow), and an oval-shaped filling defect of the ureteral orifice inside the bladder

the bladder, but no dilation of the upper urinary tract and renal pelvis (Fig. 1b). Ureteral tumour was detected preoperatively.

Ureteroscopy revealed that the right lower ureteral lumen was occupied by multiple white-grey polypoid tumours, floating in the ureter that periodically moved in and out of the bladder through the ureteral orifice. Biopsy demonstrated an inflammatory polyp. This polyp together with terminal lobulations was approximately
7.0- $\mathrm{cm}$ in length containing a large pedicle that originated from the tip of the proximal ureter. The ureteral lumen terminated at the base of the polyp, but a ureteral orifice was observed in the centre of the proximal pedicle (Fig. 2a). After exploring the interior of the pedicle by ureteroscopy (Fig. 2b), we confirmed that the upper partial pedicle was an intussuscepted segment of the ureter approximately $2.5-\mathrm{cm}$ in length and averaging 8.0 $\mathrm{mm}$ in diameter (supplementary video). The patient was
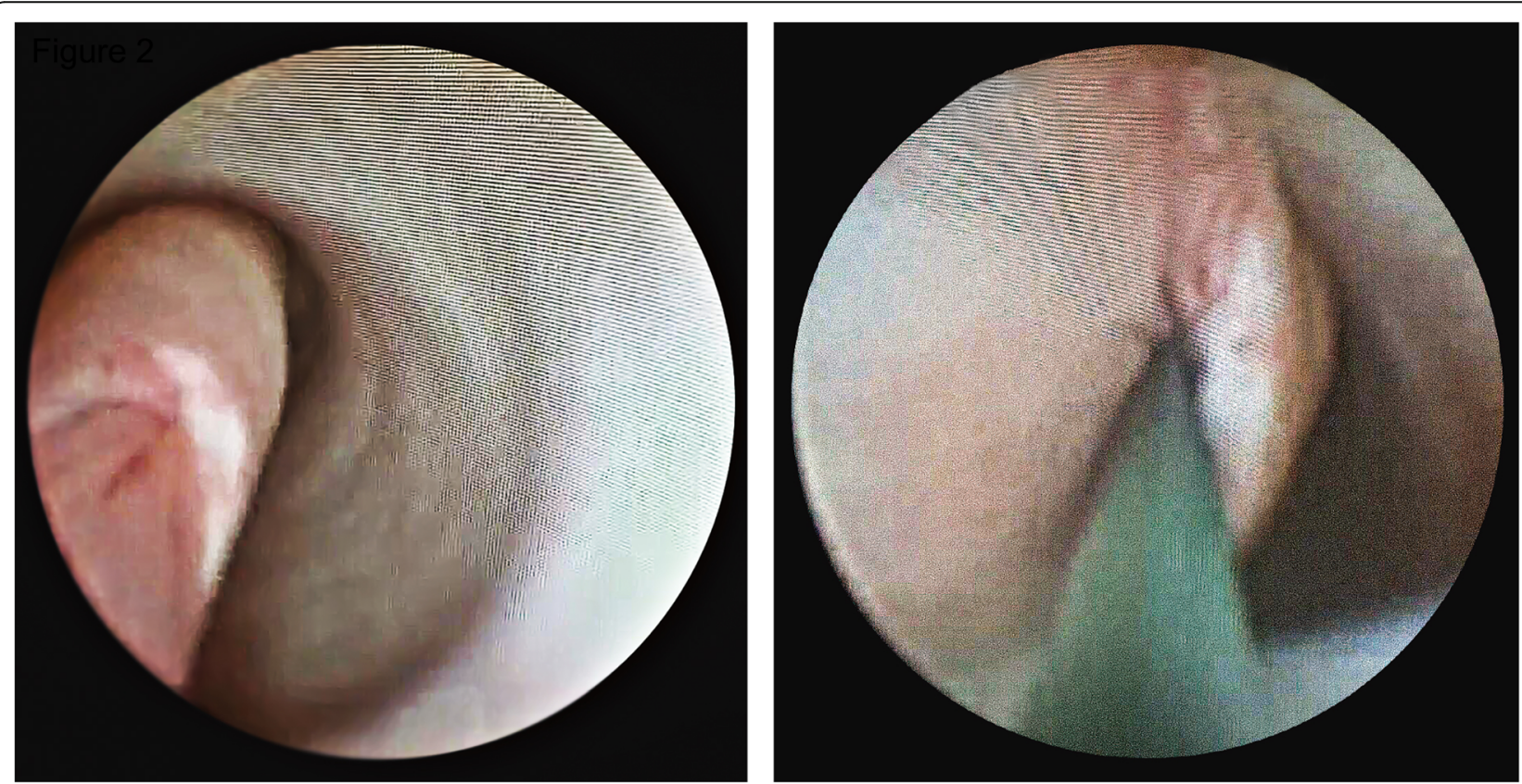

Fig. 2 Ureteroscopic view. Ureteroscopy showing an intussuscepted ureter protruding into the lumen of the adjacent segment (a); A wire was passed to the renal pelvis through the lumen of the intussusceptum (b) 
treated by ureteroscopic cauterization of the partial polyp at the slimmest point of the pedicle followed by open surgery exploration. A fusiform was found in the lower dilated thick-walled ureter and palpation revealed a firm and mobile tumour. Finally, right ureteral partial resection with reanastomosis was performed to contain the pedicle stalk and ureteral segment. Postoperative recovery was uneventful, and pathological examination confirmed a fibroepithelial polyp. The double-J stent was removed 6 weeks after the operation. A CT scan of the abdomen performed 3 months post-surgery indicated neither uronephrosis nor any signs of polyp recurrence.

\section{Discussion and conclusions}

To identify relevant studies up to May 2020, the PubMed database was searched using the terms ("ureteral" [All Fields] OR "ureter" [All Fields] OR "ureter" [MeSH Terms]) AND ("intussusception" [All Fields] OR "intussusception" [MeSH Terms]). We retrieved 101 studies, of which 28 (30 cases) that published from 1937 to 2019 were finally selected after review (Table 1). Of these, 25 cases were related to ureteral neoplasms, including 15 secondary to polyps, and 10 secondary to malignant tumours. The remaining five cases included one ureteral calculus-related case, and four cases of iatrogenic complication occurring in surgical procedures.

Ureteral intussusception does not occur spontaneously, largely because of the small ratio between ureteral wall thickness and lumen calibre and the limited range of mobility of the ureter itself, which prevents ureter invagination [25]. However, when a slow-growing object, typically a benign tumour, occupies the ureter, it draws down the proximal ureter, enters the distal dilated ureter by peristaltic activity, urine flow, and gravitational force, and sporadically leads to ureteral intussusception $[6,8,19]$ (Fig. 3). A review of previously reported cases revealed that intussusception is usually antegrade and more prevalent in men on the right side. The common manifestations in patients include a history of intermittent haematuria and repeated flank pain $[25,26]$, but malignant tumour-related ureteral intussusception is often asymptomatic and occurs uniformly in patients aged $\geq 50$ years [25]. Some scholars proposed the potential risk of ureteral ischemia because of the possible deficiency of the blood supply to the intussusceptum [28]. However, no evidence of regional ureteral ischemic necrosis associated with ureteral intussusception has been reported previously, which is compatible with the characteristic sluggish changes underlying intussusception.

Ureteral intussusception is characterized by distinct features, especially on IVU and contrast CT images that have great diagnostic value. In primary lesions, ureteral intussusception often presents a "bell-shaped [5, 21, 28]", "tongue-like [24] "or "sponge-like [23] "filling defect in an enlarged ureteral segment, with or without hydronephrosis. The intussuscepted segment filled with contrast material appears as a "line" sign [22], and the invaginated ureteral lumen appears as a "V-shaped" sign [28], also described as "claw of crab -shaped" sign in the upstream from the mass [8]. Non-contrast CT scan is helpful for revealing calculus and solid ureteral masses but can hardly detect ureteral intussusception. In contrast-enhanced CT images, contrast material opacifies both intussusceptum and distal intussuscipiens, forming a "concentric sign" [9, 22, 23, 27] or "bull's-eye sign" [25] on axial imaging, and a "stalk-of-corn" appearance on coronal and sagittal imaging [25]. Ureteroscopy and intraoperative biopsy enable definitive diagnosis and are capable of distinguishing between benign or malignant masses. Whereas adequate preoperative imaging examinations can clearly elucidate the extent of the related tumour, which is crucial in presurgical planning. Intussusception accompanied with polyps periodically protruding into the bladder is extremely rare with only three reported cases to our knowledge [23, 24, 28], and could easily be misdiagnosed as bladder tumours by ultrasonography.

In this case, partial lobulated polyps were cauterized using Holmium: YAG laser ureteroscopically, followed by open segmental resection of the ureter with reanastomosis. In the literatures, except for one case reported by F Hajji et al. which was managed by resection of the whole polyp containing the stalk by ureteroscopic electrocauterization and got a following automatic resolution of transient intussusception [28], almost all other cases of benign ureteral tumors were finally managed by surgical resection of the involved ureter with reanastomosis by open or laparoscopic approach [23, 24]. We agree that ureteroscopic cauterization is an effective and minimally invasive treatment for the management of small isolated ureteral polyps with mild and transient ureteral intussusception. However, for patients suffering from stable intussusception complicated with large polyps, it is difficult to resect ureteral lesions completely by ureteroscopic cauterization alone. Besides, because of the limited working space and the dissatisfied laser accuracy ureteroscopically, the pursuit of a perfect excision of intussusceptum will also increase the risk of ureteral perforations, postoperative lesion recurrences, and ureteral strictures. Moreover, James Sewell et al. reported the only case of ureteral calculus-related intussusception, which was treated by ureteropyeloscopic lithotripsy with Holmium: YAG laser [26]. In that case, due to the loose and short range of the intussusceptum, ureteral intussusception resolved automatically following clearance of the calculi [26]. Biopsies of the tumour and intussuscepted ureter via transurethral ureteroscopy would help rule out malignancy and signs of ischemia. The treatment 


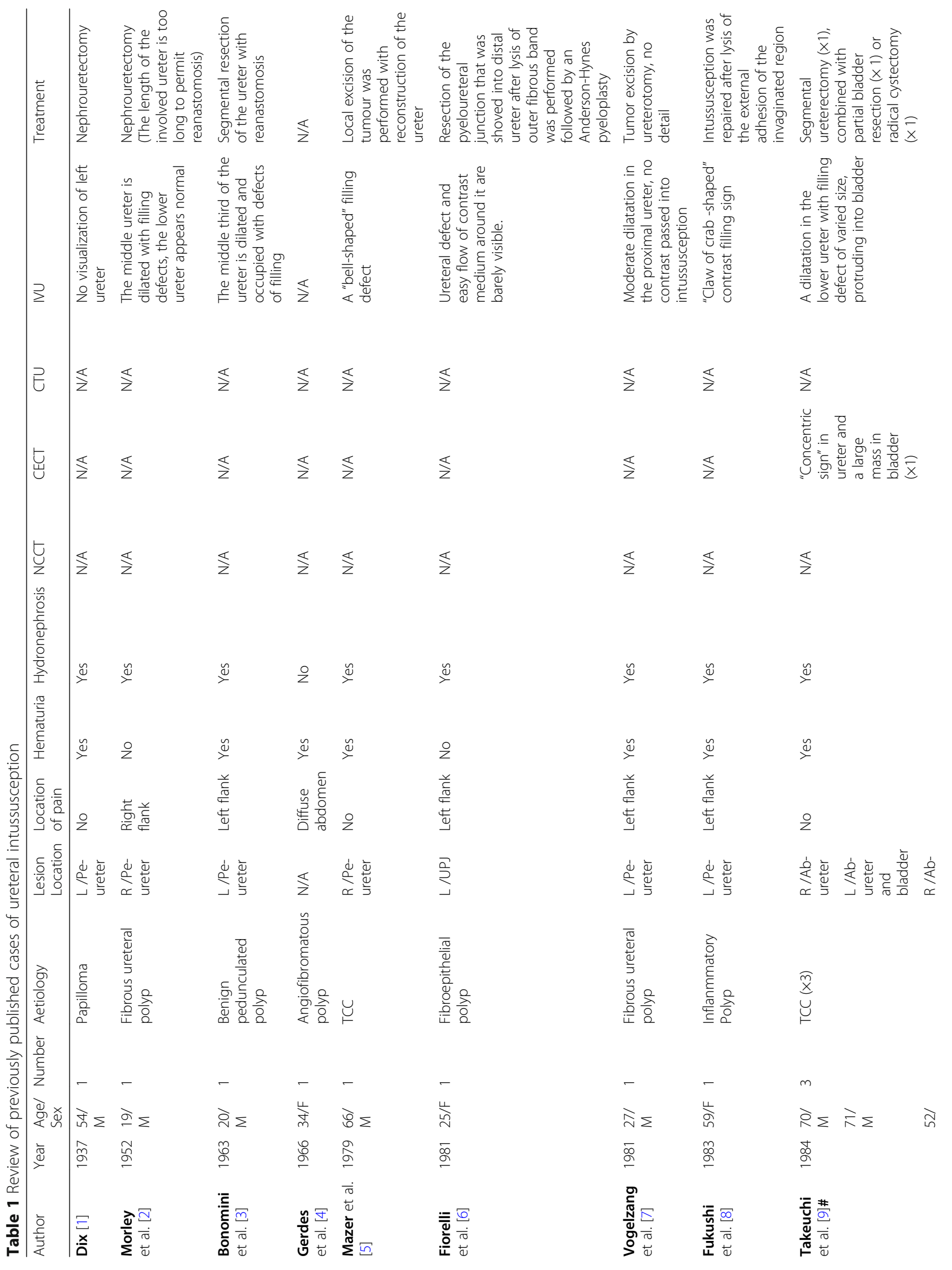


Dong et al. BMC Nephrology

(2020) 21:246

Page 5 of 9

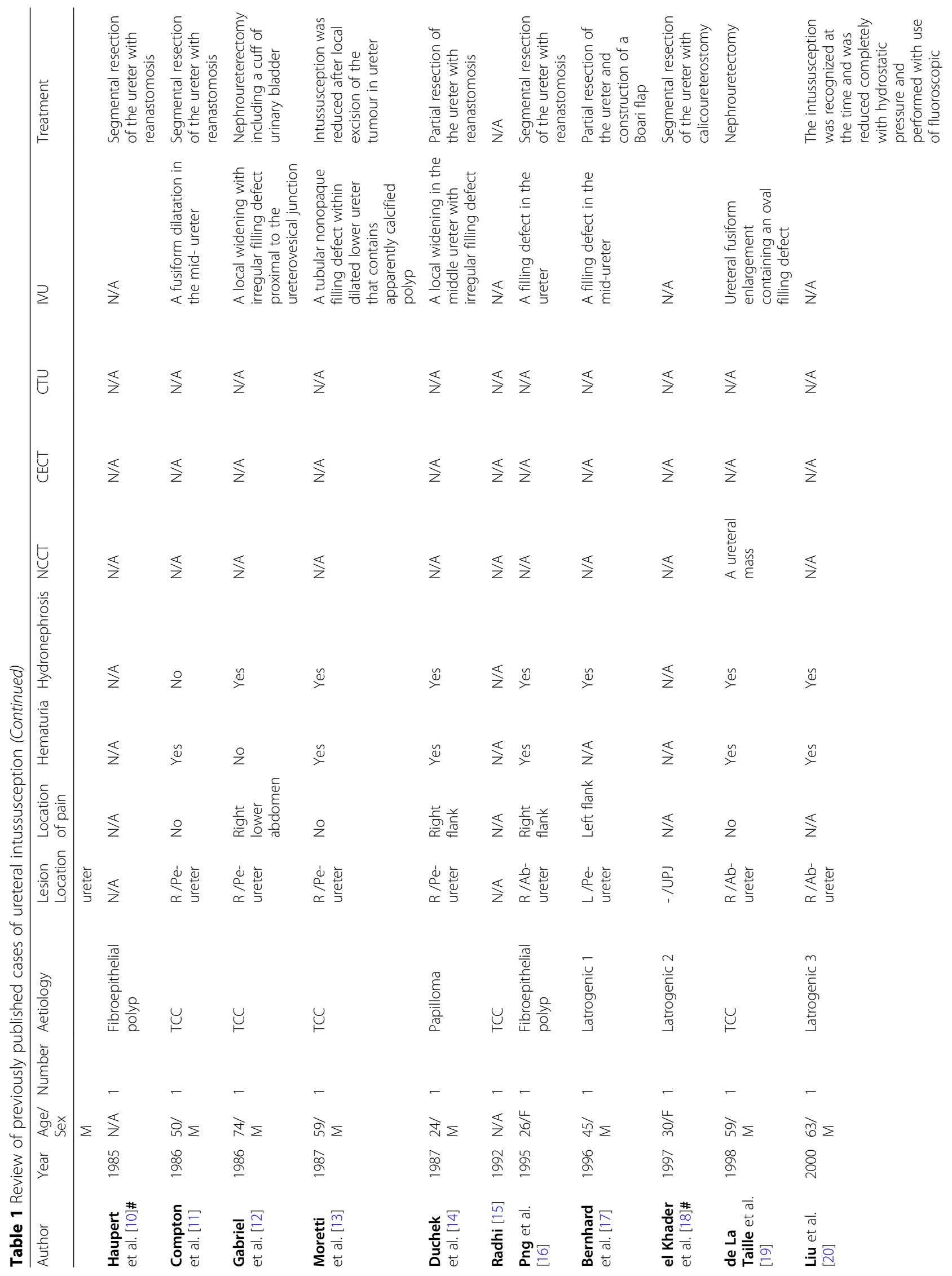




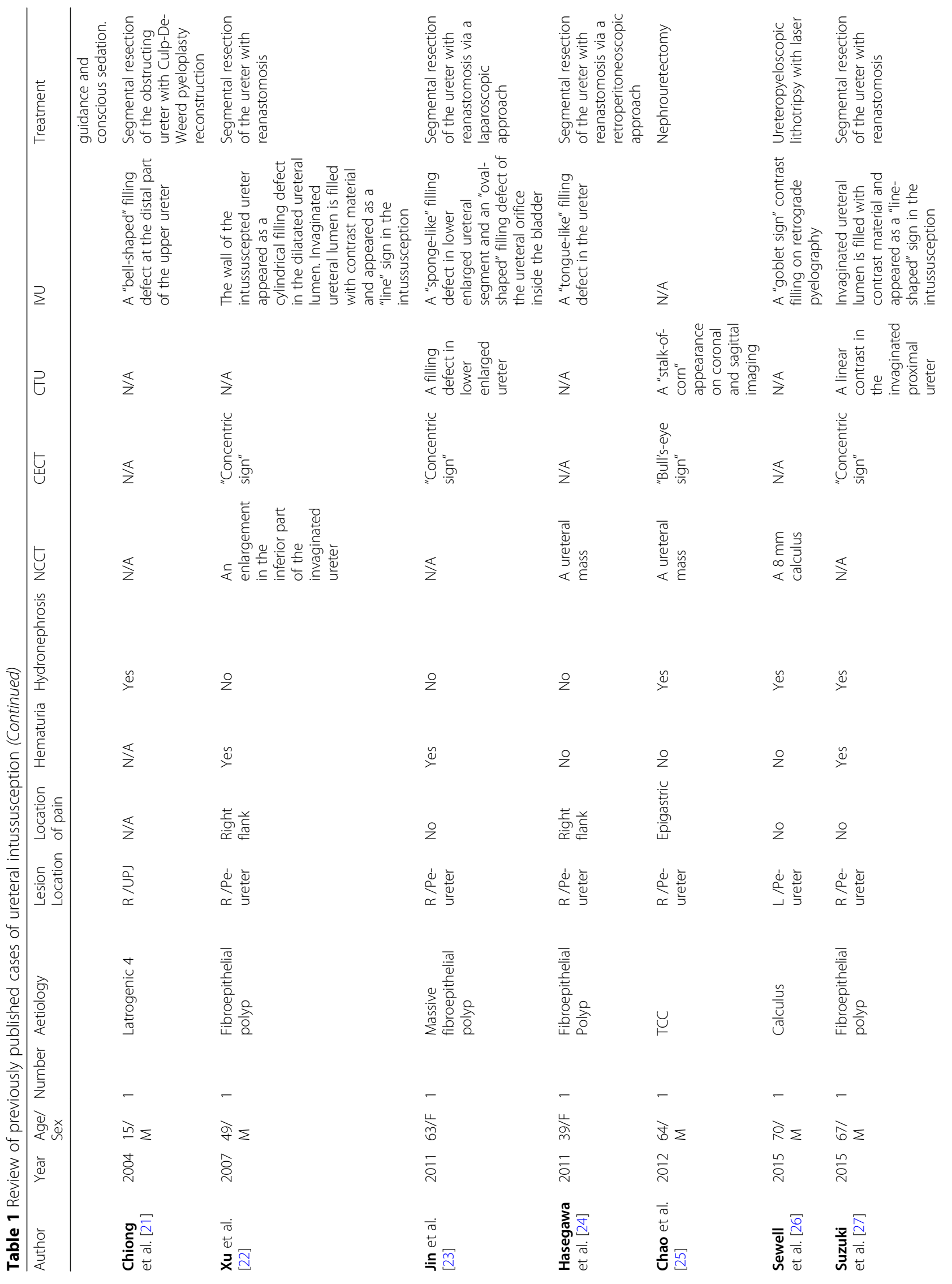




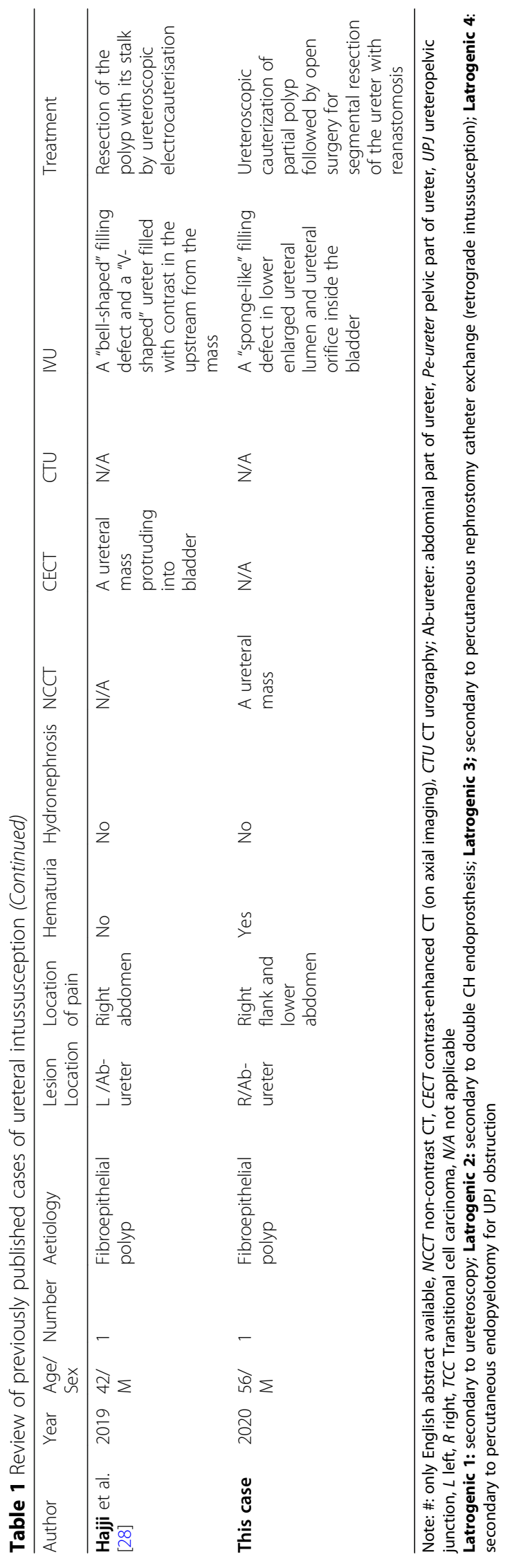



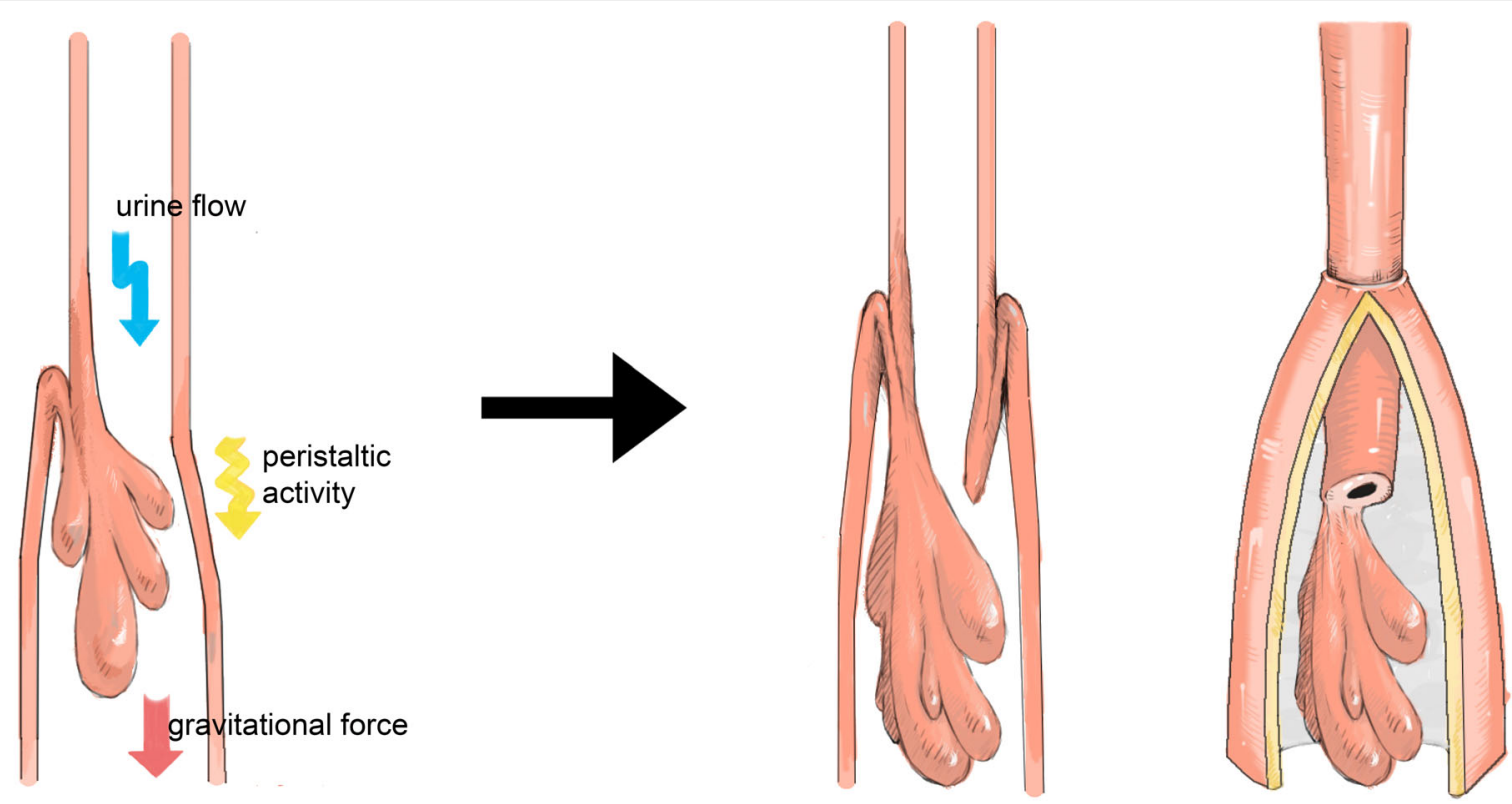

a slow-growing object occupied in ureter with the action of urine flow, peristaltic activity, and gravitational force

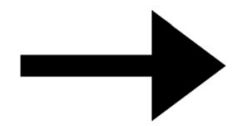

\section{Ureteral intussusception}

Fig. 3 Artist's schematic line drawing representative of the underlying pathological process

approach should be altered in accordance with the associated primary lesion, the size and location of the polyp, and the occurrence of hydronephrosis [28]. Once histological examination confirms the presence of a ureteral malignant tumour, hemiuridectomy for the urinary tract is required. Ureteral intussusception owing to benign polyps should be treated by local excision of the polyp and reconstruction of the ureter to improve ureteral patency.

In conclusion, by reviewing prior cases and presenting a typical ureteroscopic observation, we hope to increase clinical awareness to this unique condition. Ureteroscopy is vital for diagnosis as it can offer a comprehensive observation to ensure the location and size of the lesions. Extensive biopsies through ureteroscopy are necessary and should be recommended, by which excluding the presence of ureteral malignancies seems to be easier and less invasive. Based on that, treatment option as ureteroscopic cauterization, or in combination with open or laparoscopic surgical resection of segmental ureter can be formulated to benefit such patients.

\section{Supplementary information}

Supplementary information accompanies this paper at https://doi.org/10. 1186/s12882-020-01904-8.

Additional file 1: Supplementary video. A video recorded during ureteroscopy showing the characteristics of the intussuscepted segment of the ureter in the dilated ureteral lumen.
Abbreviations

CT: Computed tomography; IVU: intravenous urogram

\section{Acknowledgments}

We are grateful to this patient for participating in this study. We also like to thank nurse Rui-min Yuan for her cooperation during the operation.

\section{Declarations}

The authors of this manuscript have no conflicts of interest to disclose as described by the BMC Nephrology.

\section{Authors' contributions}

We all cared for the patient and contributed to the writing of the report. YD, WZ and TF analysed and interpreted the patient data, and drafted the original manuscript. LH and JZ created the images. $\mathrm{CH}$ devised the original idea for the report. YD, WM and $\mathrm{CH}$ revised the manuscript. Written consent for publication was obtained from the patient. All authors read and approved the final manuscript.

\section{Funding}

The medical innovation team project of Jiangsu Province (Grant No. CXTDA2017-48), the key research and development project of Jiangsu Province (Grant Nos. BE2019637 and BE2017635), and the outstanding medical talent project of Xuzhou (Grant No. 22 [2017]) provided the supporting funds for manuscript writing, English editing services, and submission review.

Availability of data and materials

All data generated or analysed during this study are included in this published article.

Ethics approval and consent to participate Not applicable.

\section{Consent for publication}

Written informed consent was obtained from the patient for publication.

\section{Competing interests}

The authors declare that they have no competing interests. 
Received: 27 January 2020 Accepted: 22 June 2020

Published online: 01 July 2020

\section{References}

1. Dix WW. Papilloma and intussusception of the ureter. Proc R Soc Med. 1937; 30:456-9.

2. Morley HV, Shumaker EJ, Gardner LW. Intussusception of the ureter associated with a benign polyp. J Urol. 1952;67:266-71

3. Bonomini B. The radiological picture of ureteral intussusceptions. Urol Int. 1963;16:268-79.

4. Gerdes G, Nordqvist L. Intussusception of the ureter caused by a primary benign tumour. Acta Chir Scand. 1966;132:397-402

5. Mazer MJ, Lacy SS, Kao L. "Bell-shaped ureter," a radiographic sign of antegrade intussusception. Urol Radiol. 1979;1:63-5.

6. Fiorelli C, Durval A, Di Cello V, et al. Ureteral intussusception by a fibroepithelial polyp. J Urol. 1981;126:110-2.

7. Vogelzang RL, Calenoff L, Bulkley GJ. Ureteral intussusception caused by fibrous ureteral polyp. Urol Radiol. 1981;3:47-9.

8. Fukushi Y, Orikasa S, Takeuchi M. A case of ureteral intussusception associated with ureteral polyp. J Urol. 1983;129:1043-4.

9. Takeuchi H, Konami T, Ikeda T, et al. Prolapse of ureteral tumor. Hinyokika Kiyo. 1984:30:787-91.

10. Haupert S, Janin-Mercier A, Camillieri L, et al. Ureteral invagination caused by a fibroepithelial polyp of the ureter: apropos of a case. Ann Urol (Paris). 1985;19:403-5

11. Compton JS, Drummond M. Intussusception of the ureter by a polypoid transitional cell carcinoma. Br J Urol. 1986;58:725-6.

12. Gabriel JB Jr, Thomas L, Guarin U, et al. Ureteral intussusception by papillary transitional cell carcinoma. Urology. 1986;28:310-2.

13. Moretti $\mathrm{KL}$, Jose JS. Ureteral intussusception owing to a malignant ureteral polyp. J Urol. 1987;137:493-4.

14. Duchek M, Hallmans G, Hietala SO, et al. Inverted papilloma with intussusception of the ureter. Scand J Urol Nephrol. 1987;21:147-9.

15. Radhi JM. Ureteral intussusception by a transitional cell carcinoma. Can J Surg. 1992;35:122-4.

16. Png JC, Tung KH. Intussusception of a ureteric polyp causing acute hydronephrosis. Br J Urol. 1995;75:801-2.

17. Bernhard PH, Reddy PK. Retrograde ureteral intussusception: a rare complication. J Endourol. 1996:10:349-51.

18. el Khader K, Koutani A, Nouri M, et al. An unusual complication of anterograde endopyelotomy: ureteral intussusception. Prog Urol. 1997;7:273-6.

19. de La Taille A, Bertrand P, Mahe P, et al. Ureteral intussusception by invasive transitional cell carcinoma. J Urol. 1998;159:505.

20. Liu DM, Torreggiani WC, Rowley VA. Hydrostatic reduction of iatrogenic intussusception of the ureter secondary to percutaneous nephrostomy catheter exchange. J Vasc Interv Radiol. 2000;11:1076-8.

21. Chiong E, Consigliere D. Antegrade ureteral intussusception: a rare complication of percutaneous endopyelotomy. Urology. 2004;64:1212-4.

22. Xu W, Yu CS, Yang L, et al. Ureteral intussusception due to a polyp. Abdom Imaging. 2007;32:675-7.

23. Jin $\mathrm{XB}$, Meng $\mathrm{HL}$, Zhang $\mathrm{YD}$, et al. Laparoscopic treatment of a massive fibroepithelial polyp accompanied by ureteral intussusception. Chin Med J. 2011;124:3436-9.

24. Hasegawa Y, Mita K, Ueki T, et al. Retroperitoneoscopic treatment of ureteral invagination caused by a long fibroepithelial polyp protruding into the bladder: report of a case. Surg Today. 2011:41:1117-21.

25. Chao CH, Fong TC, Hughes-Cassidy F, et al. Ureteral intussusception: a case report and literature review. J Comput Assist Tomogr. 2012;36:261-4.

26. Sewell J, Blecher G, Tsai K, et al. Calculus-related ureteral intussusception: a case report and literature review. Int J Surg Case Rep. 2015;12:63-6.

27. Suzuki K, Saito K, Yoshimura N, et al. Ureteral intussusception associated with a fibroepithelial polyp: a case report. Clin Imaging. 2015;39:901-3.

28. Hajji F, Moufid K, Ghoundale O, et al. A rare case of successful endoscopic management of a fibroepithelial polyp with intussusception of the ureter and periodic prolapse into bladder. Ann R Coll Surg Engl. 2019;101:e66-70.

\section{Publisher's Note}

Springer Nature remains neutral with regard to jurisdictional claims in published maps and institutional affiliations.

Ready to submit your research? Choose BMC and benefit from:

- fast, convenient online submission

- thorough peer review by experienced researchers in your field

- rapid publication on acceptance

- support for research data, including large and complex data types

- gold Open Access which fosters wider collaboration and increased citations

- maximum visibility for your research: over $100 \mathrm{M}$ website views per year

At BMC, research is always in progress.

Learn more biomedcentral.com/submissions 